\title{
Trimodal therapy vs. radical cystectomy for muscle-invasive bladder cancer:
} A Canadian cost-effectiveness analysis

Ronald Kool, MD*1; Ivan Yanev, MSc*1; Tarek Hijal, MD²; Marie Vanhuyse, MD, MSc ${ }^{3}$; Fabio L. Cury, MD ${ }^{1,2}$; Luis Souhami, MD, FASTRO ${ }^{2}$; Wassim Kassouf, MD, CM, FRCSC ${ }^{1}$; Alice Dragomir, $\mathrm{PhD}^{1}$

${ }^{1}$ Division of Urology, McGill University Health Centre, McGill University, Montreal, QC, Canada; ${ }^{2}$ Division of Radiation Oncology, McGill University Health Centre, Montreal, QC, Canada; ${ }^{3}$ Division of Medical Oncology, McGill University Health Centre, McGill University, Montreal, QC, Canada

"Equal contributors

Cite as: Kool R, Yanev I, Hijal T, et al. Trimodal therapy vs. radical cystectomy for muscleinvasive bladder cancer: A Canadian cost-effectiveness analysis. Can Urol Assoc J 2022 January 27; Epub ahead of print. http://dx.doi.org/10.5489/cuaj.7430

Published online January 27, 2022

Corresponding author: Dr. Wassim Kassouf, Division of Urology, McGill University Health Centre, Montreal, QC, Canada; wassim.kassouf.med@ssss.gouv.qc.ca

$* * *$

\section{Abstract}

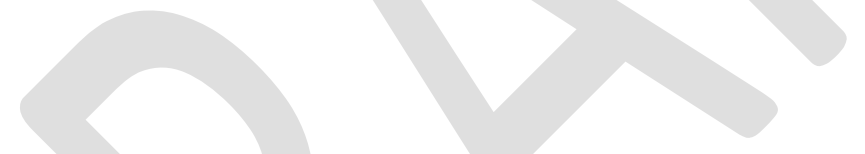

Introduction: Trimodal therapy (TMT) is a suitable alternative to neoadjuvant chemotherapy (NAC) and radical cystectomy (RC) for patients with muscle-invasive bladder cancer (MIBC). In this study, we conducted a cost-effectiveness evaluation of RC \pm NAC vs. TMT for MIBC in the universal and publicly funded Canadian healthcare system.

Methods: We developed a Markov model with Monte-Carlo microsimulations. Rates and probabilities of transitioning within different health states (e.g., cure, locoregional recurrence, distant metastasis, death) were input in the model after a scoped literature review. Two main scenarios were considered: 1) academic center; and 2) populational-level. Results were reported in life-years gained (LYG), quality-adjusted life years (QALY), and incremental costeffectiveness ratios (ICER). A sensitivity analysis was performed.

Results: A total of 20000 patients were simulated. For the academic center model, TMT was associated with increased effectiveness (both in LYG and QALY) at a higher cost compared to $\mathrm{RC} \pm \mathrm{NAC}$, at five and 10 years. This resulted in an ICER of \$19 746/QALY per patient undergoing the TMT strategy at 10 years of followup. For the populational-level model, $\mathrm{RC} \pm \mathrm{NAC}$ was associated with higher effectiveness at 10 years, with an ICER of \$3319/QALY per patient. This study was limited by heterogeneity within the studies used to build the model. 
Conclusions: In this study, TMT performed in academic centers was cost-effective compared to $\mathrm{RC} \pm \mathrm{NAC}$, with higher effectiveness at a higher cost. On the other hand, RC $\pm \mathrm{NAC}$ was considered cost-effective compared to TMT at the populational-level. Further studies are needed to confirm these results.

\section{Introduction}

On a per-patient basis from diagnosis to death, bladder cancer is an expensive malignancy to treat, and costs associated with its management have been rising continuously in the last decades $^{1}$. Muscle-invasive bladder cancer (MIBC) is the initial diagnosis in $25 \%$ of bladder cancer patients and is associated with higher rates of progression to metastatic disease, which contributes to a significant proportion of the economic burden of the disease.

Neoadjuvant chemotherapy (NAC) followed by radical cystectomy (RC) and pelvic lymph node dissection is a current standard of care for MIBC ${ }^{2}$. Trimodal therapy (TMT) consists of a maximal transurethral resection of the bladder tumor (TURBT) followed by curative-intent radiation therapy and concurrent chemotherapy. TMT has emerged as a suitable bladder-sparing alternative for properly selected patients or for those who refuse RC or are deemed non-surgical candidates $^{3}$. While no randomized controlled trials were yet successfully performed to compare both approaches, retrospective series of patients treated with TMT at high-volume academic centers have shown oncological outcomes comparable to $\mathrm{RC}^{4,5}$. In addition, $\mathrm{RC}$ appears to be associated with better long-term survival compared to TMT at the populational level when adjusted for age, comorbidities, and clinical tumour stage ${ }^{6,7}$.

In the light of increasing appeal for bladder preservation, we performed a costeffectiveness analysis to compare $\mathrm{RC} \pm \mathrm{NAC}$ vs. TMT from a healthcare system perspective in Canada regarding oncological outcomes, effectiveness, and costs at both the academic center and the populational level.

\section{Methods}

\section{Model design}

Two Markov models were built using Monte-Carlo microsimulation for a pre-set maximum period of 10 years, divided into 40 cycles of 3 months each: the academic center model and the populational level model. Health states were established to simulate the journey of MIBC patients treated with either RC \pm NAC (open technique) vs. TMT. Patients experiencing disease relapse transitioned to other health states according to further management ("intravesical therapy", "salvage RC", "first-line chemotherapy", or "second-line immunotherapy") before eventual "palliative care" and "death" from bladder cancer or from other causes. A simplified version of both models is shown (Fig. 1). 
Treatment response rates and probabilities of transitioning between health states were input in the model after a scoped literature review of MEDLINE through PubMed® using the following MeSH terms: "urinary bladder neoplasms", "urothelial cell carcinoma", "cystectomy", "combined modality therapy", "systemic therapy"; and keywords: "muscle-invasive bladder cancer", "radical cystectomy", "neoadjuvant chemotherapy", "trimodality", "trimodal therapy", "chemoradiation", "systemic therapy", "immunotherapy". Relevant studies with confirmatory references were selected (Table 1).

For the academic center model, oncological outcomes for TMT were retrieved from studies performed at high-volume academic institutions. For the populational level model, probabilities were taken from larger studies that typically included both community and academic centers. Specific parameters not available in population-based studies were kept unchanged in both models.

\section{Modeling assumptions for $R C \pm N A C$}

To incorporate a survival benefit from NAC, an absolute increase of 5-7\% in disease-free survival (DFS) rates at 5 and 10 years was applied only to a proportion of patients undergoing $\mathrm{RC}$, according to the study by Griffiths et $\mathrm{al}^{8}$. Since salvage curative options for locoregional recurrences after $\mathrm{RC} \pm \mathrm{NAC}$ (e.g. surgical resection, radiotherapy) are limited, these patients in our model were managed with first-line systemic chemotherapy (or palliative care if not eligible).

\section{Modeling assumptions for TMT}

For the TMT strategy, radiation consisted of 50 Gy delivered through intensity-modulated radiation therapy in 20 daily fractions of $2.5 \mathrm{~Gy}$ each (hypofractionated protocol). After TMT, residual non-muscle invasive bladder cancer (NMIBC) was managed with TURBT plus adjuvant intravesical BCG, with 6 weekly instillations for 6 consecutive weeks (induction) followed by 3 weekly instillations at 3, 6, and 12 months (maintenance). The 1-year BCG maintenance schedule was chosen instead of 3 years (as per guideline recommendation for high-risk NMIBC), due to the low compliance of patients when recommended for the full protocol (35\%), as reported in the literature?

A significant proportion of patients is unfit for salvage RC after TMT failure. As a result, patients with locoregional MIBC (persistent or recurrent) who were deemed non-surgical candidates were managed with systemic first-line chemotherapy or best supportive care ${ }^{10}$.

\section{Modeling assumptions for metastatic disease and palliative care}

Local but unresectable disease or distant metastasis in our model was managed with first-line cisplatin- or carboplatin-based chemotherapy ${ }^{11}$. Progression after first-line chemotherapy was managed with second-line immunotherapy ${ }^{12}$. In Canada, pembrolizumab is the main 
immunotherapy option for patients with metastatic bladder cancer and can be delivered for a maximum period of 2 years if responses are sustained. More recently, switch maintenance therapy with avelumab was approved in Canada for patients with any response or stable disease after first-line chemotherapy with a significant benefit in both progression-free (PFS) and overall survival $(\mathrm{OS})^{13}$. This strategy was integrated in sensitivity analysis - Table 4.

Palliative care consisted of the combination of an interdisciplinary approach (e.g., nutritionist, physiotherapist, psychologist), palliative surgery (e.g., emergency surgeries, endourologic procedures), and end of life management ${ }^{14}$. In our model, patients experiencing failure of previous lines of treatment or those unfit for further therapies underwent palliative care before death. Patterns, parameters, and costs of palliative care were defined using the Canadian study by de Oliveira et al. (Table 2$)^{14}$. In this study, costs were based on the median amount spent within the last 12 months of life and were reflective of services, mostly palliative, delivered to this specific population.

\section{Utilities and costs}

Utilities of 0.84 and 0.91 were set for patients with no evidence of disease after RC \pm NAC and TMT, respectively ${ }^{15}$. For the metastatic setting, utilities of 0.64 and 0.62 were used for the firstor second-line (and palliative care) settings, respectively ${ }^{16}$. Costs were retrieved from the Régie d'Assurance Maladie du Québec (RAMQ) and reported in 2019 Canadian dollars (CAD).

\section{Model calibration and sensitivity analysis}

The Markov model was tested and calibrated on overall OS and PFS, using the built-in feature of TreeAge Pro Healthcare 2020 (TreeAge Software®, Inc, Williamstown, MA). This calibration tool was carried over with the microsimulation analysis using the BOBYQA algorithm to minimize potential errors, using an $\mathrm{e}^{-10}$ relative, and an $\mathrm{e}^{-13}$ absolute optimization threshold ${ }^{17}$. The BOBYQA has the advantage of being less sensitive to local minimums in the optimization process compared to other algorithms ${ }^{17}$.

A sensitivity analysis was performed on key parameters (discounting rates, proportion of patients receiving NAC before $\mathrm{RC}$, absolute benefit of NAC on DFS rates before RC, potential use of NAC before TMT, different NAC regimens, different radiation protocols, use of switch maintenance avelumab after first-line chemotherapy, death rates for patients on palliative care, and palliative care costs), to assess for potential impacts on final model results.

\section{Results}

\section{Academic center model}

After microsimulation of 20,000 patients, OS was $66 \%$ and $44 \%$ at 5 and 10 years for RC \pm NAC and $68 \%$ and $42 \%$ at 5 and 10 years for TMT at academic centers, respectively. As a result, incremental effectiveness of $0.13 \mathrm{LYG}$ favoring the TMT approach was reported at 10 years. Regarding effectiveness in terms of QALY at 5 and 10 years, RC \pm NAC was associated with 3.35 
and 5.33, while TMT was associated with 3.63 and 5.68 QALY, respectively. As a result, an increment of 0.65 QALY at 10 years favored the TMT strategy.

Mean costs per patient associated with RC \pm NAC vs. TMT were $\$ 29,992$ (95\% CI 29,576-30,408) vs. $\$ 30,266$ (95\% CI 29,806-30,726), at 5 years and $\$ 33,286$ (95\% CI 32,798$33,774)$ vs. $\$ 40,197(95 \%$ CI 39,57-40,823) at 10 years, respectively. In comparison with RC \pm NAC, TMT had ICERs of \$979/QALY and \$19,746/QALY, at 5 and 10 years, respectively.

\section{Populational level model}

For the populational level, parameters on perioperative mortality, the proportion of patients undergoing NAC in the RC \pm NAC arm, rates of other-cause mortality, and PFS were modified in the model. In addition, the model was then further calibrated OS. Mean cost per patient for $\mathrm{RC} \pm \mathrm{NAC}$ vs. TMT at 5 years was of $\$ 38,382(95 \% \mathrm{CI} 37,798-38,966)$ vs. $\$ 39,304(95 \% \mathrm{CI}$ $38,678-39,930)$ at 5 years and of $\$ 47,391(95 \%$ CI 46,673-48,109) vs. $\$ 45,541$ (95\% CI 44,831$46,251)$ at 10 years, respectively. RC \pm NAC was the dominant strategy at 5 years, while associated with ICER of \$3,319/QALY at 10 years, compared to TMT at the populational level. Results are further detailed in Table 3.

\section{Sensitivity analysis}

Sensitivity analysis is reported in Table 4. In summary, higher effectiveness for the TMT strategy at higher costs was consistently demonstrated at academic centers with ICERs ranging from \$12,375/QALY to \$51,469/QALY. On the other hand, RC \pm NAC was associated with higher effectiveness compared to TMT at 10 years, with ICERs ranging from $\$ 812$ to $\$ 6,219$ at the populational level. Additionally, sensitivity analysis showed that $\mathrm{RC} \pm \mathrm{NAC}$ would become the dominant strategy (higher effectiveness and lower costs) in the following scenarios: no NAC for both strategies; if NAC was delivered before TMT; if palliative care costs were increased by 20\%; or if conventional fractionation (rather than hypofractionation) was utilized for the TMT strategy.

\section{Discussion}

Using a comprehensive Markov model with microsimulation built with studies performed at academic centers, TMT was cost-effective compared to RC \pm NAC with an ICER of $\$ 19,746 / \mathrm{QALY}$ per patient at 10 years. On the other hand, RC \pm NAC was associated with increased effectiveness and an ICER of \$3,319/QALY at the populational level.

\section{Oncological outcomes and effectiveness}

Historically, TMT has been mainly offered to MIBC patients who were deemed non-surgical candidates due to advanced age, limiting comorbidities, and poor performance status ${ }^{18}$. In Canada, this pattern seems to be currently shifting, as an increasing proportion of surgical candidates are now being referred to medical and radiation oncologists to be considered for bladder preservation ${ }^{19}$. The only study designed to randomize patients to RC vs. TMT (SPARE 
trial) was prematurely closed due to poor accrual ${ }^{20}$. Therefore, any attempt to compare outcomes for these two approaches is limited by retrospective design, heterogeneity, and selection bias.

In 2017, Kulkarni et al. matched 112 patients who underwent RC or TMT in a propensity score analysis, using main clinicopathological factors ${ }^{21}$. This study demonstrated comparable OS and disease-specific survival for both strategies ${ }^{21}$. Additionally, a large meta-analysis on retrospective studies (mainly from academic centers) by Fahmy et al. supported TMT as a suitable alternative to RC with comparable survival outcomes ${ }^{22}$. Using population-based data, others suggested that long-term survival rates might be inferior for TMT compared with $\mathrm{RC} \pm \mathrm{NAC}$.

Our study reinforces the comparable effectiveness of TMT in comparison to RC \pm NAC at academic centers, mimicking a scenario where patients are strictly selected. TMT was associated with a slightly improved OS rate at 5 years, while long-term survival at 10 years favored $\mathrm{RC} \pm \mathrm{NAC}$. The study by Giacalone et al. was the main source of parameters input in our TMT model, which resulted in the high effectiveness for $\mathrm{TMT}^{4}$. In that study, patients treated in the most recent era (after 2005) were mostly cT2 stage (97\%), with $88 \%$ achieving a complete response and OS at 5-year OS of 75\%. To compare TMT using this cohort of patients with favorable disease with surgery, parameters were mainly extracted from the study by Culp et al., particularly the subset of low-risk MIBC patients who underwent upfront RC without NAC and experienced 5-year OS of $64.8 \%{ }^{23}$. Given the results of these 2 pivotal studies, effectiveness in our model was higher for TMT compared to $\mathrm{RC} \pm \mathrm{NAC}$ at the academic setting. In addition, although a benefit from NAC in DFS was applied to RC patients (7\%), NAC was not included in the base case for the TMT strategy in our study, as its systematic use is still under discussion ${ }^{24}$. Nevertheless, sensitivity analysis showed that in a scenario with NAC being given to TMT patients with similar proportions and chemotherapy regimens (drugs, doses, number of cycles) as preceding RC, the difference of costs would be higher for TMT in comparison to RC $\pm \mathrm{NAC}$ at academic centers, with an ICER of \$28,726/QALY. Moreover, considering a potential lower effect of NAC in cT2 patients compared to cT3-4a or cN+ patients, sensitivity analysis with a benefit of $3 \%$ and $5 \%$ in terms of DFS at 10 years showed that TMT would be still cost-effective compared to RC \pm NAC with a higher ICER compared to the base case (Table 4).

Perhaps the most appealing benefit of TMT consists of a positive impact on the quality of life of patients who can retain their native bladder. Using a Markov model, Royce et al. have shown comparable effectiveness (in LYG) between TMT and RC \pm NAC, with an increment of up to 1.61 QALY favoring TMT during a pre-defined period of 33 years, showing the higher quality of life perceived by patients undergoing bladder preservation ${ }^{15,25}$. In our model, an incremental gain of up to 0.35 QALY was reported for TMT at 10 years in the academic centers, while for patients treated at the populational level, a better quality of life for TMT did not compensate for lower OS and effectiveness in LYG. These results suggest the impact in the quality of life for 
TMT compared to RC \pm NAC might be optimized in appropriately selected patients with a more favorable disease.

Previous RC series have shown lower surgical complication rates and improved oncological outcomes for patients operated at high-volume centers ${ }^{26,27}$. Although there are similar studies on TMT, main oncological outcomes reported in the academic setting seem to outperform the ones reported at the populational level, similarly to $\mathrm{RC}^{4,6}$. Williams et al. have shown that TMT was associated with worse OS compared to RC, particularly for patients treated with radiation delivered in less than $<27$ fractions $^{28}$. Importantly, the definition of curative bladder preservation (TMT) was challenging since doses of chemotherapy and radiotherapy were not available in the Surveillance, Epidemiology and End Results (SEER) database, leading to a proportion of patients possibly treated with palliative rather than curative intent radiation-based therapy ${ }^{28}$. Another large populational study by Seisen et al. showed that TMT was an independent factor for worse long-term OS compared to RC (HR 1,37; $p<0.001$ ), although this difference was not significant among older patients ${ }^{6}$. Granular data on baseline predictors of outcomes for TMT was unavailable in this study (e.g., completeness of initial TURBT, use of concurrent chemotherapy) which might have negatively impacted the outcomes for $\mathrm{TMT}^{6}$.

Although these comparisons at the populational level were adjusted for main clinicopathological factors (e.g., age, cT stage, comorbidities), important residual confounders were not accounted for, such as completeness of TURBT, presence of lymphovascular invasion/carcinoma in situ, radiation and concurrent chemotherapy protocols, and use of salvage RC. In addition, other confounders may play a role, such as the subjective impression of patients (e.g., frailty, performance status, preferences), physicians' personal beliefs when offering surgery vs. radiation-based therapy, academic vs. community centers' experience, and non-standardized protocols and institutional practices. Although limited by selection bias, our populational model was built on these studies published at high impact journals, and our results were also reflective of the inferior OS and effectiveness for TMT observed at the populational level.

\section{Cost-effectiveness}

To the best of our knowledge, this is the first cost-effectiveness study comparing RC $\pm \mathrm{NAC}$ vs. TMT for MIBC outside the USA. The study by Williams et al. was based on SEER, a wellrecognized populational data source in the USA ${ }^{28}$. The authors of that study showed that TMT was associated with a significantly higher cost per patient after one year of diagnosis (additional $\$ 136,935$ ) and an estimation of US\$468 million in excess for TMT in comparison to RC, considering the total USA population treated during the year $2017^{28}$. While recent studies suggest comparable oncological outcomes of TMT in Canada ${ }^{29}$, the health system these countries are in many ways different, and studies have demonstrated that general costs in the USA are mainly derived from medication and administrative expenses ${ }^{30}$. 
In our study, differences in costs associated with $\mathrm{RC} \pm \mathrm{NAC}$ and TMT were significantly lower if compared to the USA. As a result, when effectiveness was incorporated in the analysis, TMT was found to be cost-effective in Canada at academic centers. At the populational level, surgery was the dominant strategy at 5 years and slightly more expensive at 10 years. Importantly, the higher mean cost for $\mathrm{RC} \pm \mathrm{NAC}$ at 10 years might be explained not only by the initial cost of the surgery (Table 2) but also by significantly higher rates of other cause mortality and lower OS, which prevented patients from undergoing surveillance and further therapies in the TMT model (e.g., systemic therapy, sRC, palliative care) compared to RC \pm NAC.

\section{Limitations}

Our Markov model considered health states from the initial treatment until death, which resulted in significant granularity. Rates and probabilities were retrieved from different studies published in different eras, based on different populations, interventions, and methodologies, ultimately leading to heterogeneity and selection bias. Moreover, parameters related to TMT were taken from retrospective studies. To minimize the effect of significant and inevitable heterogeneity and optimize the model's precision, we sought to select studies performed at high-volume academic centers and compare these parameters with confirmatory references whenever possible. Moreover, the model was calibrated on main oncological outcomes and a sensitivity analysis including key variables that could potentially impact our base-case results was performed.

For the populational level model, limitations were even more pronounced. Several rates and probabilities, particularly DFS and PFS, were not available from population-based studies, and the model was therefore calibrated only on OS. Despite the potential impact of older age and comorbidities among TMT patients at the populational level, rates were taken from studies in which both populations were balanced. Seisen et al. reported lower OS rates for TMT with median age of 69.0 and 68.8 years old for TMT and RC patients, respectively (standardized difference $=2.1$ ), while Charlson's comorbidity index was $\geq 2$ in $8.5 \%$ and $6.9 \%$, respectively $(\text { standardized difference }=5.9)^{6}$. In addition, the study by Williams et al. reported similar proportion of patients in different age groups (66-69, 70-74, 75-79, and 80) and number of comorbidities among TMT and RC patients ${ }^{31}$.

\section{Conclusions}

TMT was found cost-effective compared to RC \pm NAC when patients are better selected and when performed at academic centers, with an estimated ICER of \$19,746/QALY. On the other hand, RC \pm NAC was cost-effective at the populational level, with an estimated ICER of $\$ 3,319$ /QALY at 10 years. These results might contribute to public health care providers when planning bladder cancer management in the future. 
Conflicts of interest: Dr. Cury reports conflicts of interest from Abbvie, Bayer, Boston Scientific, Sanofi, and Varian Medical Systems. Dr. Souhami reports conflicts of interest from Abbvie and Varian Medical Systems. The remaining authors have no conflicts of interest to declare.

\section{References}

1. Yeung C, Dinh T, Lee J. The health economics of bladder cancer: an updated review of the published literature. Pharmacoeconomics 2014;32:1093-104.

2. Kulkarni GS, Black PC, Sridhar SS, et al. Canadian Urological Association guideline: Muscle-invasive bladder cancer. Can Urol Assoc J 2019.

3. El-Achkar A, Souhami L, Kassouf W. Bladder Preservation Therapy: Review of Literature and Future Directions of Trimodal Therapy. Curr Urol Rep 2018;19:108.

4. Giacalone NJ, Shipley WU, Clayman RH, et al. Long-term Outcomes After Bladderpreserving Tri-modality Therapy for Patients with Muscle-invasive Bladder Cancer: An Updated Analysis of the Massachusetts General Hospital Experience. Eur Urol 2017;71:95260.

5. Mak RH, Hunt D, Shipley WU, et al. Long-term outcomes in patients with muscle-invasive bladder cancer after selective bladder-preserving combined-modality therapy: a pooled analysis of Radiation Therapy Oncology Group protocols 8802, 8903, 9506, 9706, 9906, and 0233. J Clin Oncol 2014;32:3801-9.

6. Seisen T, Sun M, Lipsitz SR, et al. Comparative Effectiveness of Trimodal Therapy Versus Radical Cystectomy for Localized Muscle-invasive Urothelial Carcinoma of the Bladder. Eur Urol 2017;72:483-7.

7. Cahn DB, Handorf EA, Ghiraldi EM, et al. Contemporary use trends and survival outcomes in patients undergoing radical cystectomy or bladder-preservation therapy for muscleinvasive bladder cancer. Cancer 2017;123:4337-45.

8. Griffiths G, Hall R, Sylvester R, Raghavan D, Parmar MK. International phase III trial assessing neoadjuvant cisplatin, methotrexate, and vinblastine chemotherapy for muscleinvasive bladder cancer: long-term results of the BA06 30894 trial. J Clin Oncol 2011;29:2171-7.

9. Tapiero S, Helfand A, Kedar D, et al. Patient Compliance With Maintenance Intravesical Therapy for Nonmuscle Invasive Bladder Cancer. Urology 2018;118:107-13.

10. Rodel C, Grabenbauer GG, Kuhn R, et al. Combined-modality treatment and selective organ preservation in invasive bladder cancer: long-term results. Journal of clinical oncology : official journal of the American Society of Clinical Oncology 2002;20:3061-71.

11. Bamias A, Tzannis K, Harshman LC, et al. Impact of contemporary patterns of chemotherapy utilization on survival in patients with advanced cancer of the urinary tract: a Retrospective International Study of Invasive/Advanced Cancer of the Urothelium (RISC). Ann Oncol 2018;29:361-9.

12. Fradet Y, Bellmunt J, Vaughn DJ, et al. Randomized phase III KEYNOTE-045 trial of pembrolizumab versus paclitaxel, docetaxel, or vinflunine in recurrent advanced urothelial cancer: results of > 2 years of follow-up. Ann Oncol 2019. 
13. Powles T, Park SH, Voog E, et al. Avelumab Maintenance Therapy for Advanced or Metastatic Urothelial Carcinoma. N Engl J Med 2020;383:1218-30.

14. de Oliveira C, Pataky R, Bremner KE, et al. Phase-specific and lifetime costs of cancer care in Ontario, Canada. BMC Cancer 2016;16:809.

15. Mak KS, Smith AB, Eidelman A, et al. Quality of Life in Long-term Survivors of MuscleInvasive Bladder Cancer. International journal of radiation oncology, biology, physics 2016;96:1028-36.

16. Stevenson SM, Danzig MR, Ghandour RA, et al. Cost-effectiveness of neoadjuvant chemotherapy before radical cystectomy for muscle-invasive bladder cancer. Urol Oncol 2014;32:1172-7.

17. Powell MJD. "The BOBYQA algorithm for bound constrained optimization without derivatives." Cambridge NA Report NA2009/06, University of Cambridge, Cambridge. 2009.

18. Gray PJ, Fedewa SA, Shipley WU, et al. Use of potentially curative therapies for muscleinvasive bladder cancer in the United States: results from the National Cancer Data Base. European urology 2013;63:823-9.

19. Wei X, Siemens DR, Mackillop WJ, Booth CM. Use of radiotherapy for bladder cancer: A population-based study of evolving referral and practice patterns. Can Urol Assoc J 2019;13:92-101.

20. Huddart RA, Birtle A, Maynard L, et al. Clinical and patient-reported outcomes of SPARE a randomised feasibility study of selective bladder preservation versus radical cystectomy. BJU Int 2017;120:639-50.

21. Kulkarni GS, Hermanns T, Wei Y, et al. Propensity Score Analysis of Radical Cystectomy Versus Bladder-Sparing Trimodal Therapy in the Setting of a Multidisciplinary Bladder Cancer Clinic. J Clin Oncol 2017;35:2299-305.

22. Fahmy O, Khairul-Asri MG, Schubert T, et al. A systematic review and meta-analysis on the oncological long-term outcomes after trimodality therapy and radical cystectomy with or without neoadjuvant chemotherapy for muscle-invasive bladder cancer. Urol Oncol 2018;36:43-53.

23. Culp SH, Dickstein RJ, Grossman HB, et al. Refining patient selection for neoadjuvant chemotherapy before radical cystectomy. The Journal of urology 2014;191:40-7.

24. Royce TJ, Liu Y, Milowsky MI, et al. Trimodality Therapy With or Without Neoadjuvant Chemotherapy for Muscle-Invasive Bladder Cancer. Clin Genitourin Cancer 2021.

25. Royce TJ, Feldman AS, Mossanen M, et al. Comparative Effectiveness of Bladderpreserving Tri-modality Therapy Versus Radical Cystectomy for Muscle-invasive Bladder Cancer. Clin Genitourin Cancer 2019;17:23-31.e3.

26. Nielsen ME, Mallin K, Weaver MA, et al. Association of hospital volume with conditional 90-day mortality after cystectomy: an analysis of the National Cancer Data Base. BJU international 2014;114:46-55.

27. Scarberry K, Berger NG, Scarberry KB, et al. Improved surgical outcomes following radical cystectomy at high-volume centers influence overall survival. Urol Oncol 2018;36:308.e11.e17. 
28. Williams SB, Shan Y, Ray-Zack MD, et al. Comparison of Costs of Radical Cystectomy vs Trimodal Therapy for Patients With Localized Muscle-Invasive Bladder Cancer. JAMA Surg 2019:e191629.

29. Kool* R, Marcq G, Busca I, et al. PD60-01\&\#x2003;DEFINITIVE RADIATION-BASED THERAPY FOR MUSCLE-INVASIVE BLADDER CANCER: THE CANADIAN MULTICENTER EXPERIENCE. Journal of Urology 2020;203:e1273-e.

30. Papanicolas I, Woskie LR, Jha AK. Health Care Spending in the United States and Other High-Income Countries. JAMA 2018;319:1024-39.

31. Williams SB, Shan Y, Jazzar U, et al. Comparing Survival Outcomes and Costs Associated With Radical Cystectomy and Trimodal Therapy for Older Adults With Muscle-Invasive Bladder Cancer. JAMA Surg 2018;153:881-9.

32. Hermans TJN, Fransen van de Putte EE, Horenblas S, et al. Perioperative treatment and radical cystectomy for bladder cancer--a population based trend analysis of 10,338 patients in the Netherlands. Eur J Cancer 2016;54:18-26.

33. El-Gehani F, North S, Ghosh S, Venner P. Improving the outcome of patients with muscle invasive urothelial carcinoma of the bladder with neoadjuvant gemcitabine/cisplatin chemotherapy: A single institution experience. Can Urol Assoc J 2014;8:e287-93.

34. Booth CM, Karim S, Brennan K, Siemens DR, Peng Y, Mackillop WJ. Perioperative chemotherapy for bladder cancer in the general population: Are practice patterns finally changing? Urologic Oncology: Seminars and Original Investigations 2018;36:89.e1389.e20.

35. Galsky MD, Pal SK, Chowdhury S, et al. Comparative effectiveness of gemcitabine plus cisplatin versus methotrexate, vinblastine, doxorubicin, plus cisplatin as neoadjuvant therapy for muscle-invasive bladder cancer. Cancer 2015;121:2586-93.

36. Yafi FA, Aprikian AG, Chin JL, et al. Contemporary outcomes of 2287 patients with bladder cancer who were treated with radical cystectomy: a Canadian multicentre experience. BJU international 2011;108:539-45.

37. Waingankar N, Mallin K, Smaldone M, et al. Assessing the relative influence of hospital and surgeon volume on short-term mortality after radical cystectomy. BJU International 2017;120:239-45.

38. Hautmann RE, de Petriconi RC, Pfeiffer C, Volkmer BG. Radical cystectomy for urothelial carcinoma of the bladder without neoadjuvant or adjuvant therapy: long-term results in 1100 patients. European urology 2012;61:1039-47.

39. Grossman HB, Natale RB, Tangen CM, et al. Neoadjuvant chemotherapy plus cystectomy compared with cystectomy alone for locally advanced bladder cancer. N Engl J Med 2003;349:859-66.

40. Bekelman JE, Handorf EA, Guzzo T, et al. Radical cystectomy versus bladder-preserving therapy for muscle-invasive urothelial carcinoma: examining confounding and misclassification biasin cancer observational comparative effectiveness research. Value Health 2013;16:610-8.

41. Eswara JR, Efstathiou JA, Heney NM, et al. Complications and long-term results of salvage cystectomy after failed bladder sparing therapy for muscle invasive bladder cancer. The Journal of urology 2012;187:463-8. 
42. Sanchez A, Wszolek MF, Niemierko A, et al. Incidence, Clinicopathological Risk Factors, Management and Outcomes of Nonmuscle Invasive Recurrence after Complete Response to Trimodality Therapy for Muscle Invasive Bladder Cancer. The Journal of urology 2018;199:407-15.

43. Zietman AL, Grocela J, Zehr E, et al. Selective bladder conservation using transurethral resection, chemotherapy, and radiation: management and consequences of Ta, T1, and Tis recurrence within the retained bladder. Urology 2001;58:380-5.

44. Robinson AG, Wei X, Vera-Badillo FE, Mackillop WJ, Booth CM. Palliative Chemotherapy for Bladder Cancer: Treatment Delivery and Outcomes in the General Population. Clin Genitourin Cancer 2017;15:e535-e41.

45. Dogliotti L, Carteni G, Siena S, et al. Gemcitabine plus cisplatin versus gemcitabine plus carboplatin as first-line chemotherapy in advanced transitional cell carcinoma of the urothelium: results of a randomized phase 2 trial. European urology 2007;52:134-41.

46. von der Maase H, Sengelov L, Roberts JT, et al. Long-term survival results of a randomized trial comparing gemcitabine plus cisplatin, with methotrexate, vinblastine, doxorubicin, plus cisplatin in patients with bladder cancer. Journal of clinical oncology : official journal of the American Society of Clinical Oncology 2005;23:4602-8.

47. De Santis M, Bellmunt J, Mead G, et al. Randomized phase II/III trial assessing gemcitabine/carboplatin and methotrexate/carboplatin/vinblastine in patients with advanced urothelial cancer who are unfit for cisplatin-based chemotherapy: EORTC study 30986. J Clin Oncol 2012;30:191-9.

48. Powles T, Duran I, van der Heijden MS, et al. Atezolizumab versus chemotherapy in patients with platinum-treated locally advanced or metastatic urothelial carcinoma (IMvigor211): a multicentre, open-label, phase 3 randomised controlled trial. Lancet (London, England) 2018;391:748-57.

49. Bellmunt J, Theodore C, Demkov T, et al. Phase III trial of vinflunine plus best supportive care compared with best supportive care alone after a platinum-containing regimen in patients with advanced transitional cell carcinoma of the urothelial tract. Journal of clinical oncology : official journal of the American Society of Clinical Oncology 2009;27:4454-61.

50. Flannery K, Cao X, He J, Zhong Y, Shah AY, Kamat AM. Survival Rates and Health Care Costs for Patients With Advanced Bladder Cancer Treated and Untreated With Chemotherapy. Clin Genitourin Cancer 2018;16:e909-e17.

51. Santos F, Dragomir A, Zakaria AS, Kassouf W, Aprikian A. Predictors of costs associated with radical cystectomy for bladder cancer: A population-based retrospective cohort study in the province of Quebec, Canada. J Surg Oncol 2016;113:223-8. 


\section{Figures and Tables}

Fig. 1. Simplified Markov models for (a) radical cystectomy (RC) \pm neoadjuvant chemotherapy (NAC); and (b) trimodal therapy (TMT).

a)

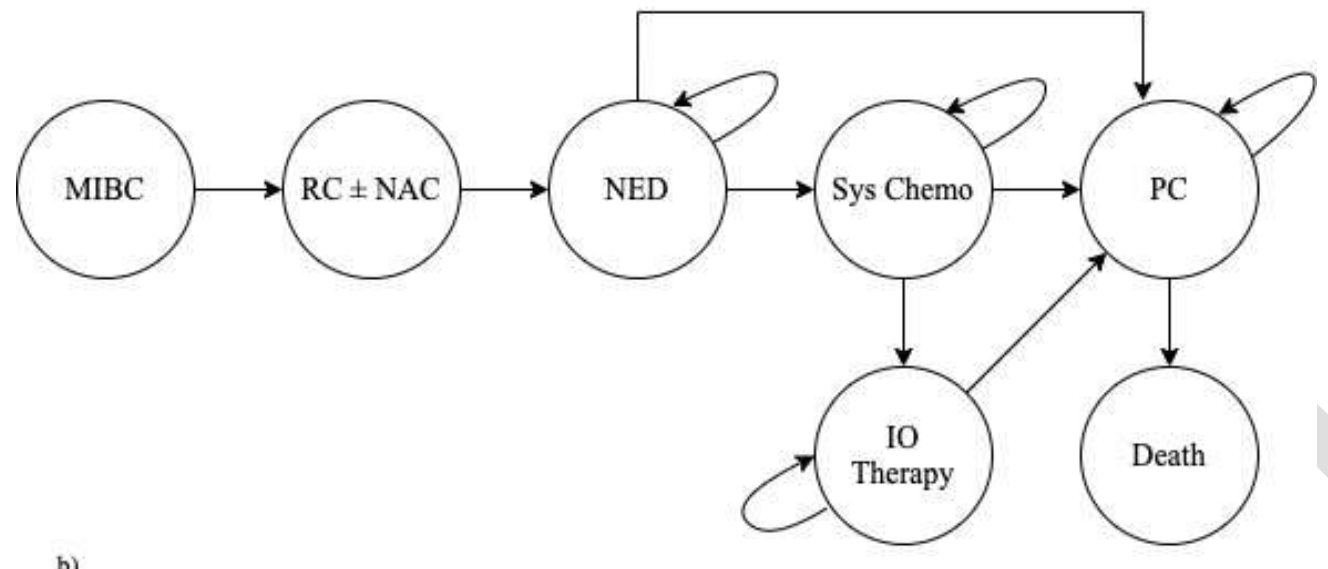

b)

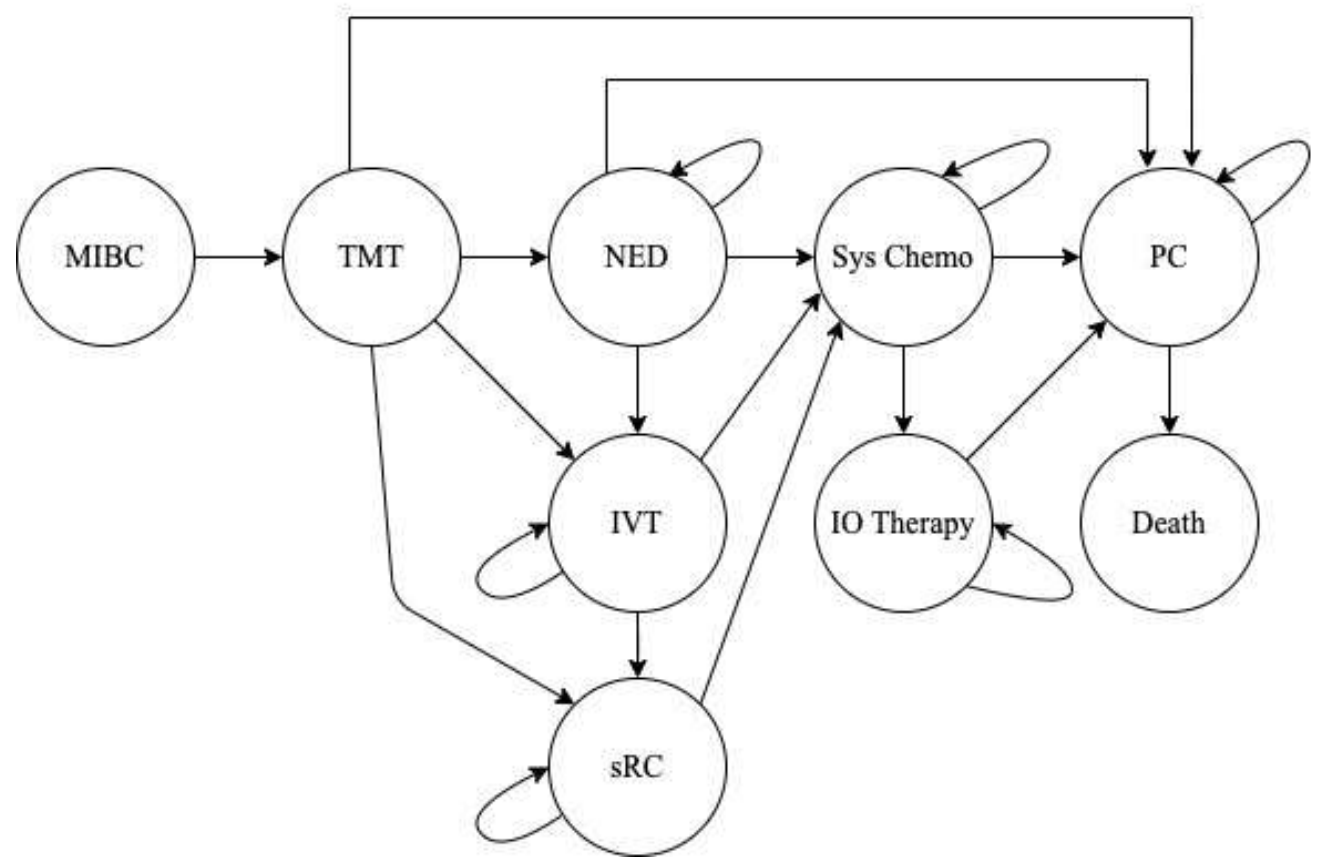

Arrows represent transitions between health states. Patients can transition from every state to death (arrows were omitted for graphic simplicity). IO: immuno-oncology; IVT: intravesical therapy; MIBC: muscle-invasive bladder cancer; NED: no evidence of disease; PC: palliative care; sRC: salvage radical cystectomy; Sys Chemo: systemic chemotherapy. 


\begin{tabular}{|c|c|c|c|}
\hline \multicolumn{4}{|l|}{ Radical cystectomy } \\
\hline Rates and probabilities & Base case & References & $\begin{array}{l}\text { Confirmatory } \\
\text { base case }\end{array}$ \\
\hline $\begin{array}{l}\text { Proportion of patients } \\
\text { receiving NAC } \\
-\quad \text { Academic centers } \\
-\quad \text { Populational-level }\end{array}$ & $\begin{array}{l}49 \% \\
27 \%\end{array}$ & $\begin{array}{l}\text { Hermans et al }{ }^{32} \\
\text { Booth et } \mathrm{al}^{34}\end{array}$ & $\begin{array}{l}57 \%^{33} \\
- \\
\end{array}$ \\
\hline $\begin{aligned} & \text { NAC regimen } \\
&- \text { ddMVAC } \\
&- \text { Gemcitabine + } \\
& \text { cisplatin }\end{aligned}$ & $\begin{array}{l}39 \% \\
61 \%\end{array}$ & $\begin{array}{l}\text { Galsky et al }{ }^{35} \\
\text { Galsky et } \mathrm{al}^{35}\end{array}$ & $\begin{array}{l}- \\
-\end{array}$ \\
\hline 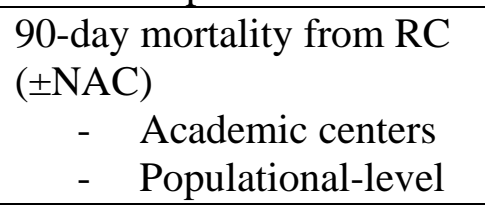 & $\begin{array}{l}3.2 \% \\
7.2 \% \\
\end{array}$ & $\begin{array}{l}\text { Yafi et al }{ }^{36} \\
\text { Waingankar et al }{ }^{37}\end{array}$ & $\begin{array}{l}3.7 \%^{8} \\
-\quad \\
\end{array}$ \\
\hline $\begin{aligned} \text { RFS after RC } \pm \text { NAC } \\
-\quad 5 y \\
-\quad 10 y \\
\end{aligned}$ & $\begin{array}{l}83.6 \% \\
79.6 \% \\
\end{array}$ & $\begin{array}{l}\text { Culp et } \mathrm{al}^{23} \\
\text { Culp et } \mathrm{al}^{23}\end{array}$ & $\begin{array}{l}69.5 \%^{38} \\
65.5 \%^{38} \\
\end{array}$ \\
\hline $\begin{array}{l}\text { OS after RC }( \pm \text { NAC }) \\
\text { Academic centers } \\
-\quad 5 \text { years } \\
-\quad 10 \text { years } \\
\text { Populational-level } \\
-\quad 5 \text { years } \\
-\quad 10 \text { years } \\
\end{array}$ & $\begin{array}{l}68.3 \% \\
49.0 \% \\
43.5 \% \\
24.1 \% \\
\end{array}$ & $\begin{array}{l}\text { Culp et } \mathrm{al}^{23} \\
\text { Culp et } \mathrm{al}^{23} \\
\text { Seisen et } \mathrm{al}^{6} \\
\text { Seisen et } \mathrm{al}^{6}\end{array}$ & $\begin{array}{l}57 \% \%^{39} \\
45 \%^{39} \\
40.1 \%^{31} \\
21.5 \%^{31} \\
\end{array}$ \\
\hline $\begin{array}{l}\text { Other-cause mortality after } \\
\text { RC } \\
\text { Academic centers } \\
\quad-\quad 5 \text { years } \\
-\quad 10 \text { years } \\
\text { Populational-level } \\
-\quad 5 \text { years } \\
-\quad 10 \text { years }\end{array}$ & $\begin{array}{l}18.4 \% \\
35.1 \% \\
19.6 \% \\
35.4 \% \\
\end{array}$ & $\begin{array}{l}\text { Culp et } \mathrm{al}^{23} \\
\text { Culp et } \mathrm{al}^{23} \\
\\
\text { Williams et } \mathrm{al}^{31} \\
\text { Williams et } \mathrm{al}^{31}\end{array}$ & $\begin{array}{l}13.3^{38} \\
22.5^{38} \\
18.0 \%^{40} \\
33.3 \%^{40}\end{array}$ \\
\hline \multicolumn{4}{|l|}{ Trimodal therapy } \\
\hline Rates and probabilities & Base case & References & $\begin{array}{l}\text { Confirmatory } \\
\text { references }\end{array}$ \\
\hline $\begin{array}{l}\text { Complete response after } \\
\text { TMT }\end{array}$ & $75 \%$ & Giacalone et $\mathrm{al}^{4}$ & $69-72 \%{ }^{5,10}$ \\
\hline Death from TMT & $0.24 \%$ & Rodel et al ${ }^{10}$ & $0 \%{ }^{4}$ \\
\hline Residual disease after TMT & $25 \%$ & Giacalone et al ${ }^{4}$ & $28-31 \% \%^{5,10}$ \\
\hline
\end{tabular}




\begin{tabular}{|c|c|c|c|}
\hline $\begin{array}{ll}\text { - } & \text { Residual NMIBC } \\
\text { - } & \text { Residual MIBC } \\
\end{array}$ & $\begin{array}{l}18.2 \% \\
81.8 \% \\
\end{array}$ & $\begin{array}{l}\text { Rodel et al } \\
\text { Rodel et al } \\
\text { 10 }\end{array}$ & - \\
\hline sRC rates & $31 \%$ & ${\text { Giacalone et } \mathrm{al}^{4}}^{4}$ & $20-21 \%^{10}$ \\
\hline 90-day mortality from sRC & $2.2 \%$ & Eswara et $\mathrm{al}^{41}$ & - \\
\hline $\begin{array}{l}\text { Residual disease post-TMT - } \\
\text { no treatment }\end{array}$ & $41.4 \%$ & Giacalone et $\mathrm{al}^{4}$ & $54.4 \%^{10}$ \\
\hline $\begin{array}{c}\text { Recurrence rates after CR } \\
\text { - } \quad \text { NMIBC } \\
5 \text { years } \\
10 \text { years } \\
\text { - MIBC } \\
5 \text { years } \\
10 \text { years } \\
\text { - Distant metastasis } \\
5 \text { years } \\
10 \text { years } \\
\end{array}$ & $\begin{array}{l}26 \% \\
26 \% \\
16 \% \\
18 \% \\
44 \% \\
49 \% \\
\end{array}$ & $\begin{array}{l}\text { Giacalone et } \mathrm{al}^{4} \\
\text { Giacalone et } \mathrm{al}^{4} \\
\text { Giacalone et } \mathrm{al}^{4} \\
\text { Giacalone et } \mathrm{al}^{4} \\
\text { Giacalone et } \mathrm{al}^{4} \\
\text { Giacalone et } \mathrm{al}^{4}\end{array}$ & $\begin{array}{l}31 \%^{5} \\
36 \%^{5} \\
13 \%^{5} \\
14 \%^{5} \\
44 \%^{5} \\
51 \%^{5} \\
\end{array}$ \\
\hline $\begin{array}{l}\text { Management of NMIBC } \\
\text { recurrence after CR: } \\
-\quad \text { RFS after IVT (3y) } \\
\text { - } \quad \text { sRC rate post-IVT } \\
\text { Management of MIBC } \\
\text { recurrence after CR: } \\
\quad \text { - } \quad \text { sRC } \\
-\quad 11^{\text {st }} \text {-line chemotherapy }\end{array}$ & $\begin{array}{l}82.4 \% \\
17.6 \% \\
\end{array}$ & $\begin{array}{l}\text { Sanchez et al } \\
\text { Zietman et }^{42}{ }^{43} \\
\text { Rodel et al } \\
\text { Rodel et al }\end{array}$ & $\begin{array}{l}- \\
40.9 \% \\
42\end{array}$ \\
\hline $\begin{array}{l}\text { RFS after immediate sRC: } \\
-\quad 5 \text { years } \\
-\quad 10 \text { years } \\
\text { RFS after delayed sRC: } \\
\begin{aligned}- & 5 \text { years } \\
- & 10 \text { years }\end{aligned}\end{array}$ & $\begin{array}{l}58.6 \% \\
28.2 \% \\
64.5 \% \\
61.1 \% \\
\end{array}$ & $\begin{array}{l}\text { Eswara et al }{ }^{41} \\
\text { Eswara et al }^{41} \\
\text { Eswara et al } \\
\text { Eswara et } \mathrm{al}^{41}\end{array}$ & $\begin{array}{l}51 \%^{4} \\
32 \%^{4} \\
64 \%^{4} \\
64 \%^{4}\end{array}$ \\
\hline $\begin{array}{l}\text { OS after TMT } \\
\text { Academic centers } \\
-\quad 5 \text { years } \\
-\quad 10 \text { years } \\
\text { Populational-level } \\
-\quad 5 \text { years } \\
-\quad 10 \text { years }\end{array}$ & $\begin{array}{l}75 \% \\
67 \% \\
35 \% \\
16 \% \\
\end{array}$ & $\begin{array}{l}\text { Giacalone et } \mathrm{al}^{4} \\
\text { Giacalone et } \mathrm{al}^{4} \\
\text { Seisen et } \mathrm{al}^{6} \\
\text { Seisen et } \mathrm{al}^{6}\end{array}$ & $\begin{array}{l}57 \%^{5} \\
36 \%^{5} \\
23.5 \%^{31} \\
7.8 \%{ }^{31}\end{array}$ \\
\hline $\begin{array}{l}\text { Other-cause mortality after } \\
\text { TMT } \\
\text { Academic centers } \\
\quad-\quad 5 \text { years } \\
\quad-\quad 10 \text { years } \\
\text { Populational-level }\end{array}$ & $\begin{array}{l}9 \% \\
20 \%\end{array}$ & $\begin{array}{l}\text { Giacalone et } \mathrm{al}^{4} \\
\text { Giacalone et } \mathrm{al}^{4}\end{array}$ & - \\
\hline
\end{tabular}




\begin{tabular}{|c|c|c|c|}
\hline $\begin{array}{ll}- & 5 \text { years } \\
- & 10 \text { years }\end{array}$ & $\begin{array}{l}23.8 \% \\
32.9 \%\end{array}$ & $\begin{array}{l}\text { Williams et } \mathrm{al}^{31} \\
\text { Williams et } \mathrm{al}^{31}\end{array}$ & $\begin{array}{l}- \\
-\end{array}$ \\
\hline \multicolumn{4}{|l|}{ Systemic disease } \\
\hline Rates and probabilities & Base case & References & \begin{tabular}{|l} 
Confirmatory \\
references
\end{tabular} \\
\hline $\begin{aligned} 1^{\text {st }} \text {-line CHT } & \text { Cisplatin-based } \\
- & \text { Carboplatin-based }\end{aligned}$ & $\begin{array}{l}74.3 \% \\
62.5 \% \\
37.5 \%\end{array}$ & 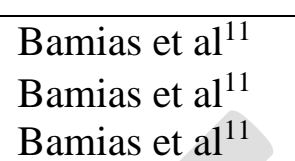 & $\begin{array}{l}- \\
72.6^{44} \\
27.4^{44}\end{array}$ \\
\hline $\begin{array}{l}\text { PFS on } 1^{\text {st }-l i n e ~ C H T ~}-1 \text { year } \\
-\quad \text { GEM/CIS } \\
-\quad \text { GEM/Carboplatin }\end{array}$ & $\begin{array}{l}26.4 \% \\
18.5 \%\end{array}$ & $\begin{array}{l}\text { Dogliotti et al }{ }^{45} \\
\text { Dogliotti et } \mathrm{al}^{45}\end{array}$ & - \\
\hline $\begin{aligned} \text { OS on } & { }^{\text {st }} \text { line CHT - } 1 \text { year } \\
- & \text { GEM/CIS } \\
- & \text { GEM/Carboplatin }\end{aligned}$ & $\begin{array}{l}63.7 \% \\
37.5 \%\end{array}$ & $\begin{array}{l}\text { Dogliotti et al } 4^{45} \\
\text { Dogliotti et al }\end{array}$ & $\begin{array}{l}58.4 \% 46 \\
37.0 \% \%^{47}\end{array}$ \\
\hline $\begin{array}{l}\text { PFS on } 2^{\text {nd }}-\text { line systemic } \\
\text { therapy }{ }^{*}-1 \text { year }\end{array}$ & $18.2 \%$ & Fradet et $\mathrm{al}^{12}$ & $20.7 \%^{48}$ \\
\hline $\begin{array}{l}\text { OS on } 2^{\text {nd }}-\text { line systemic } \\
\text { therapy }^{*}-1 \text { year }\end{array}$ & $44.2 \%$ & ${\text { Fradet et } \mathrm{al}^{12}}^{12}$ & $39.2 \%{ }^{48}$ \\
\hline $\begin{array}{l}\text { OS on palliative care }-2 \\
\text { years }\end{array}$ & $7 \%$ & Bellmunt et al $^{49}$ & $6 \%^{50}$ \\
\hline
\end{tabular}

"Pembrolizumab. ${ }^{\dagger}$ Additional $4 \%$ decrease in PFS from 5 to 10 years was applied using results from Hautmann et al. ${ }^{38}$ CHT: chemotherapy; CIS: cisplatin; CR: complete response; GEM: gemcitabine; IVT: intravesical therapy; MIBC: muscle-invasive bladder cancer; NAC: neoadjuvant chemotherapy; NMIBC: non-muscle-invasive bladder cancer; OS: overall survival;PFS: progression-free survival; RC: radical cystectomy; RFS: recurrence-free survival; sRC: salvage radical cystectomy; TMT: trimodal therapy; TURBT: transurethral resection of the bladder tumor. 


\begin{tabular}{|c|c|}
\hline Procedure & Unit cost ${ }^{\dagger}$ \\
\hline TURBT & $\$ 1872$ \\
\hline NAC & \\
\hline $\begin{array}{ll}\text { - } & \text { ddMVAC } \\
- & \text { Gemcitabine + Cisplatin }\end{array}$ & $\begin{array}{l}\$ 3600 \text { (per cycle) } \\
\$ 808(\text { per cycle })\end{array}$ \\
\hline Radical cystectomy & $\$ 19409$ (Santos, et al $\left.{ }^{51}\right)$ \\
\hline Radiotherapy & $\$ 5558$ (per treatment) \\
\hline $\begin{array}{cl}\text { Concurrent chemotherapy } \\
- & \text { Gemcitabine } \\
- & \text { Cisplatin } \\
- & 5 \mathrm{FU}+\mathrm{MMC} \\
\end{array}$ & $\begin{array}{l}\$ 362 \text { (per cycle) } \\
\$ 534 \text { (per cycle) } \\
\$ 993(\text { per cycle) }\end{array}$ \\
\hline $\begin{aligned} & \text { Followup } \\
& \text { - } \text { Consultation } \\
&- \text { Imaging } \\
&- \text { Laboratory } \\
&- \text { Cystoscopy } \\
&- \text { Urine cytology }\end{aligned}$ & $\begin{array}{l}\$ 48 \\
\$ 1,144 \\
\$ 25 \\
\$ 350 \\
\$ 92\end{array}$ \\
\hline $\begin{array}{c}\text { Intravesical therapy } \\
-\quad \text { BCG }\end{array}$ & $\$ 237$ (per dose) \\
\hline $\begin{aligned} \text { Chemotherapy } \\
-\quad \text { Gemcitabine + Cisplatin } \\
-\quad \text { Gemcitabine + Carboplatin }\end{aligned}$ & $\begin{array}{l}\$ 4846 \text { (per treatment) } \\
\$ 2342 \text { (per treatment) }\end{array}$ \\
\hline Immunotherapy (Pembrolizumab) & $\$ 8800$ (per dose) \\
\hline Palliative care (until death) & $\$ 10271$ (de Oliveira et al ${ }^{14}$ ) \\
\hline
\end{tabular}

${ }^{\dagger}$ Costs presented in Canadian dollars (CAD) and retrieved from the "Liste de médicament - Régie d'assurance maladie du Québec (RAMQ)" or the Pharmacy department at the McGill University Health Center, Montreal, QC. BCG: bacillus Calmete-Guérin; ddMVAC: dose-dense methotrexate + vinblastine + adriamycin + cisplatin; MMC: mitomycin; NAC: neoadjuvant chemotherapy; TURBT: transurethral resection of bladder tumor; 5FU: 5-flouracil. 


\begin{tabular}{|c|c|c|c|c|c|c|}
\hline \multirow[b]{2}{*}{ Parameters } & \multicolumn{3}{|c|}{ Academic center } & \multicolumn{3}{|c|}{ Population-level } \\
\hline & $\mathrm{RC} \pm \mathrm{NAC}$ & TMT & $\begin{array}{l}\text { Increment } \\
\text { (TMT - } \\
\text { RC } \pm \text { NAC) }\end{array}$ & $\begin{array}{l}\mathrm{RC} \pm \mathrm{NA} \\
\mathrm{C}\end{array}$ & TMT & \begin{tabular}{|l|} 
Increment \\
(TMT - \\
RC \pm NAC)
\end{tabular} \\
\hline $\begin{aligned} & \text { LYG } \\
&- 5 y \\
&- 10 y \\
&\end{aligned}$ & $\begin{array}{l}4.00 \\
6.40 \\
\end{array}$ & $\begin{array}{l}4.15 \\
6.53 \\
\end{array}$ & $\begin{array}{r}+0.15 \\
+0.13 \\
\end{array}$ & $\begin{array}{l}3.43 \\
4.88 \\
\end{array}$ & $\begin{array}{l}3.11 \\
4.16 \\
\end{array}$ & \begin{tabular}{|l|}
-0.32 \\
-0.72 \\
\end{tabular} \\
\hline $\begin{aligned} \text { QALY } & \\
- & 5 \mathrm{y} \\
- & 10 \mathrm{y}\end{aligned}$ & $\begin{array}{l}3.35 \\
5.33 \\
\end{array}$ & $\begin{array}{l}3.63 \\
5.68 \\
\end{array}$ & $\begin{array}{r}+0.28 \\
+0.35 \\
\end{array}$ & $\begin{array}{l}2.80 \\
4.02 \\
\end{array}$ & $\begin{array}{l}2.60 \\
3.46 \\
\end{array}$ & \begin{tabular}{|l}
-0.20 \\
-0.58 \\
\end{tabular} \\
\hline $\begin{array}{c}\text { Costs }^{\dagger} \\
-\quad 5 y \\
-\quad 10 y\end{array}$ & $\begin{array}{l}\$ 29,992 \\
\$ 33,286\end{array}$ & $\begin{array}{l}\$ 30,266 \\
\$ 40,197\end{array}$ & $\begin{array}{l}\$ 274 \\
\$ 6,911\end{array}$ & $\begin{array}{l}\$ 38,382 \\
\$ 47,391\end{array}$ & $\begin{array}{l}\$ 39,304 \\
\$ 45,541\end{array}$ & $\begin{array}{l}\$ 922 \\
-\$ 1,850\end{array}$ \\
\hline $\begin{aligned} \text { OS }(\%) \\
-\quad 5 y \\
-\quad 10 y\end{aligned}$ & $\begin{array}{l}66.0 \\
44.0\end{array}$ & $\begin{array}{l}68.0 \\
42.0\end{array}$ & $\begin{array}{l}+2.0 \\
-2.0\end{array}$ & $\begin{array}{l}44.0 \\
24.0\end{array}$ & \begin{tabular}{|l}
34.0 \\
17.0
\end{tabular} & \begin{tabular}{|l}
-10.0 \\
-7.0
\end{tabular} \\
\hline $\begin{aligned} \text { PFS } & (\%) \\
- & 5 \mathrm{y} \\
- & 10 \mathrm{y}\end{aligned}$ & $\begin{array}{l}62.0 \\
42.0\end{array}$ & $\begin{array}{l}62.0 \\
39.0 \\
\end{array}$ & $\begin{array}{l}0.0 \\
+3.0\end{array}$ & $\begin{array}{l}36.0 \\
22.0\end{array}$ & $\begin{array}{l}27.0 \\
15.0\end{array}$ & \begin{tabular}{|l|}
-9.0 \\
-7.0
\end{tabular} \\
\hline
\end{tabular}

${ }^{\dagger}$ Costs presented in Canadian dollars (CAD); mean cost per patient.

LYG: life-years gained; NAC: neoadjuvant chemotherapy; OS: overall survival; PFS:

progression-free survival; QALY: quality-adjusted life-years; RC: radical cystectomy. 


\begin{tabular}{|c|c|c|c|c|}
\hline Variables and variations & $\begin{array}{l}\text { Incremental } \\
\text { cost }^{\dagger}\end{array}$ & $\begin{array}{l}\text { Incremental } \\
\text { QALYS }\end{array}$ & $\begin{array}{l}\text { Favorable } \\
\text { strategy }\end{array}$ & $\begin{array}{l}\text { TMT vs. RC } \\
\text { ICER }\end{array}$ \\
\hline $\begin{array}{l}\text { Base case }(10 \mathrm{y}) \\
\text { Academic centers } \\
\text { Populational level } \\
\end{array}$ & \begin{tabular}{|l|}
$\$ 6911$ \\
$-\$ 1850$ \\
\end{tabular} & $\begin{array}{l}0.35 \\
-0.56 \\
\end{array}$ & $\begin{array}{l}\text { TMT } \\
\text { RC }\end{array}$ & $\begin{array}{l}\$ 19746 \\
\$ 3319 \\
\end{array}$ \\
\hline $\begin{array}{l}\text { Discount rate } \\
\text { Academic centers } \\
0 \% \\
3 \% \\
5 \% \\
\text { Populational-level } \\
0 \% \\
3 \% \\
5 \% \\
\end{array}$ & $\begin{array}{l}\$ 7463 \\
\$ 5072 \\
\$ 4589 \\
\\
-\$ 796 \\
-\$ 411 \\
-\$ 1424 \\
\end{array}$ & $\begin{array}{l}0.15 \\
0.38 \\
0.30 \\
-0.58 \\
-0.43 \\
-0.42 \\
\end{array}$ & $\begin{array}{l}\text { TMT } \\
\text { TMT } \\
\text { TMT } \\
\text { RC } \\
\text { RC } \\
\text { RC } \\
\end{array}$ & $\begin{array}{l}\$ 51469 \\
\$ 13436 \\
\$ 15556 \\
\\
\$ 1378 \\
\$ 950 \\
\$ 3431 \\
\end{array}$ \\
\hline $\begin{array}{l}\% \text { of NAC (RC modality) } \\
\text { Academic centers } \\
0 \% \\
27 \% \\
57 \% \\
\text { Populational-level } \\
0 \% \\
27 \% \\
57 \% \\
\end{array}$ & $\begin{array}{l}\$ 8090 \\
\$ 6821 \\
\$ 6351 \\
\\
\$ 1060 \\
-\$ 1850 \\
-\$ 2923 \\
\end{array}$ & $\begin{array}{l}0.48 \\
0.42 \\
0.33 \\
\\
-0.39 \\
-0.56 \\
-0.47 \\
\end{array}$ & $\begin{array}{l}\text { TMT } \\
\text { TMT } \\
\text { TMT } \\
\text { RC } \\
\text { RC } \\
\text { RC } \\
\end{array}$ & $\begin{array}{l}\$ 16942 \\
\$ 16436 \\
\$ 19245 \\
\\
\text { Dominated } \\
\$ 3319 \\
\$ 6219 \\
\end{array}$ \\
\hline $\begin{array}{l}\text { NAC regimen (RC modality) } \\
\text { Academic centers } \\
31 \% \text { ddMVAC/69\% Gem-Cis } \\
21 \% \text { ddMVAC/79\% Gem-Cis } \\
41 \% \text { ddMVAC/59\% Gem-Cis } \\
\text { Populational-level } \\
31 \% \text { ddMVAC/69\% Gem-Cis } \\
21 \% \text { ddMVAC/79\% Gem-Cis } \\
41 \% \text { ddMVAC/59\% Gem-Cis }\end{array}$ & $\begin{array}{l}\$ 5742 \\
\$ 6541 \\
\$ 4950 \\
\\
-\$ 837 \\
-\$ 772 \\
\end{array}$ & $\begin{array}{l}0.43 \\
0.37 \\
0.40 \\
\\
\\
-0.45 \\
-0.52 \\
\end{array}$ & $\begin{array}{l}\text { TMT } \\
\text { TMT } \\
\text { TMT } \\
\\
\text { RC } \\
\text { RC } \\
\end{array}$ & $\begin{array}{l}\$ 13353 \\
\$ 17560 \\
\$ 12375 \\
\\
\\
\$ 1860 \\
\$ 1485 \\
\end{array}$ \\
\hline $\begin{array}{l}\text { DFS benefit after NAC } \\
\text { Academic centers } \\
3 \% \\
5 \%\end{array}$ & $\begin{array}{l}\$ 12927 \\
\$ 13036\end{array}$ & $\begin{array}{l}0.39 \\
0.32\end{array}$ & $\begin{array}{l}\text { TMT } \\
\text { TMT }\end{array}$ & $\begin{array}{l}\$ 33576 \\
\$ 40111\end{array}$ \\
\hline $\begin{array}{l}\text { NAC included as option before TMT } \\
\text { Academic centers } \\
\text { Populational-level }\end{array}$ & $\begin{array}{l}\$ 11634 \\
\$ 2995\end{array}$ & $\begin{array}{l}0.41 \\
-0.43\end{array}$ & $\begin{array}{l}\text { TMT } \\
\text { RC }\end{array}$ & $\begin{array}{l}\$ 28726 \\
\text { Dominated }\end{array}$ \\
\hline $\begin{array}{l}\text { Radiation protocol with } 64 \mathrm{G}(32 \\
\text { fractions) } \\
\text { Academic centers }\end{array}$ & $\$ 9979$ & 0.39 & TMT & \$25 919 \\
\hline
\end{tabular}




\begin{tabular}{|c|c|c|c|c|}
\hline Populational-level & $\$ 3743$ & -0.46 & $\mathrm{RC}$ & Dominated \\
\hline \multirow{2}{*}{\multicolumn{5}{|c|}{$\begin{array}{l}\text { Utilities } \\
\text { Academic centers }\end{array}$}} \\
\hline & & & & \\
\hline $80 \%$ & $\$ 6569$ & 0.28 & TMT & $\$ 23461$ \\
\hline $90 \%$ & $\$ 6634$ & 0.35 & TMT & $\$ 19091$ \\
\hline $110 \%$ & $\$ 5544$ & 0.39 & TMT & $\$ 14215$ \\
\hline $120 \%$ & $\$ 6724$ & 0.43 & TMT & $\$ 15637$ \\
\hline \multicolumn{5}{|l|}{ Populational-level } \\
\hline $80 \%$ & $-\$ 321$ & -0.40 & $\mathrm{RC}$ & $\$ 813$ \\
\hline $90 \%$ & $-\$ 533$ & -0.40 & $\mathrm{RC}$ & $\$ 1333$ \\
\hline $110 \%$ & $-\$ 1608$ & -0.55 & $\mathrm{RC}$ & $\$ 2950$ \\
\hline $120 \%$ & $-\$ 1112$ & -0.84 & $\mathrm{RC}$ & $\$ 1320$ \\
\hline \multicolumn{5}{|l|}{ Avelumab switch maintenance } \\
\hline \multicolumn{5}{|l|}{ Palliative care cost } \\
\hline \multicolumn{5}{|l|}{ Academic centers } \\
\hline $80 \%$ & $\$ 5561$ & 0.39 & TMT & $\$ 14168$ \\
\hline $90 \%$ & $\$ 6013$ & 0.35 & TMT & $\$ 17058$ \\
\hline $110 \%$ & $\$ 6382$ & 0.39 & TMT & $\$ 16577$ \\
\hline $120 \%$ & $\$ 6038$ & 0.37 & TMT & $\$ 16542$ \\
\hline \multicolumn{5}{|l|}{ Populational-level } \\
\hline $80 \%$ & $-\$ 1551$ & -0.49 & $\mathrm{RC}$ & $\$ 3165$ \\
\hline $90 \%$ & $-\$ 1061$ & -0.49 & $\mathrm{RC}$ & $\$ 2165$ \\
\hline $110 \%$ & $-\$ 477$ & -0.52 & $\mathrm{RC}$ & $\$ 926$ \\
\hline $120 \%$ & $\$ 644$ & -0.48 & $\mathrm{RC}$ & Dominated \\
\hline \multicolumn{5}{|l|}{ Palliative care death rate } \\
\hline $80 \%$ & $\$ 6180$ & 0.34 & TMT & $\$ 18311$ \\
\hline $90 \%$ & $\$ 6424$ & 0.31 & TMT & $\$ 20557$ \\
\hline $110 \%$ & $\$ 5544$ & 0.39 & TMT & $\$ 14125$ \\
\hline $120 \%$ & $\$ 6724$ & 0.38 & TMT & $\$ 17931$ \\
\hline \multicolumn{5}{|l|}{ Populational level } \\
\hline $80 \%$ & $-\$ 968$ & -0.45 & $\mathrm{RC}$ & $\$ 2163$ \\
\hline $90 \%$ & $-\$ 780$ & -0.52 & $\mathrm{RC}$ & $\$ 1493$ \\
\hline $110 \%$ & $-\$ 345$ & -0.43 & $\mathrm{RC}$ & $\$ 812$ \\
\hline $120 \%$ & $-\$ 436$ & -0.44 & $\mathrm{RC}$ & $\$ 985$ \\
\hline
\end{tabular}

${ }^{\dagger}$ Costs in Canadian dollars (CAD); ${ }^{\star}$ Canadian dollars/QALY per patient; increment = TMT RC. ddMVAC: dose-dense combination of methotrexate, vinblastine, adriamycin, and cisplatin; DFS: disease-free survival; Gem-Cis: combination of gemcitabine and cisplatin; ICER: incremental cost-effectiveness ratio; NAC: neoadjuvant chemotherapy; QALY: quality-adjusted life years; RC: radical cystectomy; TMT: trimodal therapy. 